\title{
A survey of the awareness, knowledge, policies and views of veterinary journal Editors-in-Chief on reporting guidelines for publication of research
}

\author{
Douglas JC Grindlay ${ }^{1 *}$, Rachel S Dean ${ }^{1}$, Mary M Christopher ${ }^{2}$ and Marnie L Brennan
}

\begin{abstract}
Background: Wider adoption of reporting guidelines by veterinary journals could improve the quality of published veterinary research. The aims of this study were to assess the knowledge and views of veterinary Editors-in-Chief on reporting guidelines, identify the policies of their journals, and determine their information needs. Editors-in-Chief of 185 journals on the contact list for the International Association of Veterinary Editors (IAVE) were surveyed in April 2012 using an online questionnaire which contained both closed and open questions.

Results: The response rate was 36.8\% (68/185). Thirty-six of 68 editors (52.9\%) stated they knew what a reporting guideline was before receiving the questionnaire. Editors said they had found out about reporting guidelines primarily through articles in other journals, via the Internet and through their own journal. Twenty of 57 respondents (35.1\%) said their journal referred to reporting guidelines in its instructions to authors. CONSORT, REFLECT, and ARRIVE were the most frequently cited. Forty-four of 68 respondents (68.2\%) believed that reporting guidelines should be adopted by all refereed veterinary journals. Qualitative analysis of the open questions revealed that lack of knowledge, fear, resistance to change, and difficulty in implementation were perceived as barriers to the adoption of reporting guidelines by journals. Editors suggested that reporting guidelines be promoted through communication and education of the veterinary community, with roles for the IAVE and universities. Many respondents believed a consensus policy on guideline implementation was needed for veterinary journals.
\end{abstract}

Conclusions: Further communication and education about reporting guidelines for editors, authors and reviewers has the potential to increase their adoption by veterinary journals in the future.

Keywords: Veterinary journals, Veterinary research, Reporting guidelines, Reporting quality, Editors, Editorial policies, Views, Barriers

\section{Background}

Reporting guidelines, standards or statements (referred to here as reporting guidelines) can be defined as "statements that provide advice on how to report research methods and findings" [1]. The aim of reporting guidelines is to improve the transparency, accuracy and completeness of reporting for different types of research studies, ultimately improving the reliability and value of published research $[1,2]$. Reporting guidelines have been implemented by many medical journals and there have

\footnotetext{
* Correspondence: douglas.grindlay@nottingham.ac.uk

${ }^{1}$ Centre for Evidence-based Veterinary Medicine, School of Veterinary Medicine and Science, The University of Nottingham, Sutton Bonington Campus, Loughborough LE12 5RD, UK

Full list of author information is available at the end of the article
}

been calls for wider adoption of these tools [3,4]. Several studies have found that the quality of reported research was improved in journals that had adopted reporting guidelines [5-8].

Around 200 reporting guidelines are listed on the website of the EQUATOR Network [9], which promotes their development and dissemination. Popham and colleagues [10] identified five "core" reporting guidelines relating to major research designs: CONSORT for randomised controlled trials [11], TREND for non-randomised controlled trials [12], STROBE for observational studies in epidemiology [13], PRISMA for systematic reviews and meta-analyses [14] and STARD for studies of diagnostic accuracy [15]. Two additional reporting guidelines are specifically relevant for veterinary medicine: REFLECT for randomised controlled 
trials for livestock and food safety [16] and ARRIVE for research using laboratory animals [17]. The International Association of Veterinary Editors (IAVE) has also published a consensus reporting guideline on animal ethics and welfare that addresses the use of client-owned animals [18].

Several authors have demonstrated deficiencies in the reporting of study design features and other methodological information necessary to judge the quality of the evidence in veterinary research, especially in clinical trials [19-23]. For more than a decade, commentaries have called for the adoption of reporting guidelines by veterinary journals to improve the quality of published research and enable more effective critical appraisal [2,24-33]. More [2] recommended that veterinary journals "require author compliance" with relevant reporting guidelines. However, the general awareness of veterinary journal editors about reporting guidelines and the extent to which veterinary journals have implemented reporting guidelines is unknown.

EQUATOR is currently investigating the factors that prevent or facilitate the use of reporting guidelines by medical journals [3]. Corresponding information is lacking on potential barriers and facilitating factors in the implementation of reporting guidelines by veterinary journals. The aims of this study were to assess the knowledge and views of Editors-in-Chief of veterinary journals about reporting guidelines, and to identify current and planned journal policies on the implementation of reporting guidelines. A further aim was to assess the information needs of editors in relation to reporting guidelines, and how these could best be met.

\section{Methods}

This research received ethical approval from the School of Veterinary Medicine and Science Ethics Committee at The University of Nottingham. As stated in the introductory letter of the online questionnaire (Additional file 1), consent to participate in the research was implied by completion of the questionnaire. No incentives were offered for participation. In reporting this study, reference was made to the checklist of items in the STROBE statement [13].

\section{Sample selection}

The reference population for this cross-sectional study was Editors-in-Chief of veterinary journals and of animal science journals that publish papers of relevance to veterinary medicine and science. The sampling frame was Editors-in-Chief of journals on the contact list for the IAVE for whom a valid e-mail address was available. This contact list is maintained by the Organising Chair of the IAVE (MC), through a combination of direct communication with veterinary editors and information obtained from bibliographic databases and journal websites.
The IAVE e-mail contact list used for the survey invitation was updated as of $1^{\text {st }}$ April 2012, and included Editors-in-Chief from 197 journals. For journals with more than one Editor-in-Chief, the editors were asked in both the invitation e-mail and the introductory letter to return a single, joint response for their journal.

\section{Questionnaire development}

The questionnaire was made anonymous to encourage full and accurate responses; however respondents had the option to provide identifying information at the end of the questionnaire. The introductory letter explained the purpose of the study and listed the investigators involved.

The online questionnaire was developed and hosted using Cvent Web Survey software (Cvent, Inc., McLean, VA, USA; www.cvent.com). The text of the questionnaire is shown in Additional file 1. The questionnaire included closed, semi-closed and open questions that were organized in the following five sections:

Section 1 - The respondent's present knowledge of reporting guidelines;

Section 2 - Current and planned implementation of reporting guidelines by the respondent's journal;

Section 3 - The respondent's views on the potential need for reporting guidelines and their implementation by veterinary journals;

Section 4 - The respondent's information needs concerning reporting guidelines;

Section 5 - Optional identifying information, including the country the journal was published in and the name of the journal.

The first question in the questionnaire ("Before receiving this questionnaire, did you know what a reporting guideline/standard was?") was compulsory. Respondents answering "Yes" to this question were asked how and where they had learned about reporting guidelines and which reporting guidelines they were aware of, from a list of options. Respondents answering "No" were directed to Section 2 and the next compulsory question for all respondents, on whether their journal's instructions to authors mentioned reporting guidelines. Different questions were posed to respondents whose journal already referred to reporting guidelines than to those whose journal did not. At the start of Section 2, a brief definition of reporting guidelines was given to inform any respondents previously unaware of what they were. Respondents were instructed to consult their journal's editorial team if they lacked the information to answer the questions on their journal's current and planned implementation of reporting guidelines. 
The questionnaire was pre-tested by seven researchers from the Centre for Evidence-based Veterinary Medicine and then piloted online by three Assistant Editors and a former Editor-in-Chief of veterinary journals, and five veterinary researchers from the University of Nottingham. It was ensured that the logic of the online questionnaire functioned correctly, and any ambiguous or misunderstood questions were re-worded.

\section{Questionnaire distribution}

Editors-in-Chief on the IAVE contact list were e-mailed an invitation to take part in the survey by MC on behalf of the IAVE on 18 April 2012. The invitation included a brief description of the study and a link to the online questionnaire. If an e-mail failure message was received after sending out the initial invitation, the e-mail was resent to the same address two days later. If the e-mail failed a second time, an attempt was made to find an alternative e-mail address by searching the journal's website, and the invitation was resent if another address was found. Reminders were sent to all recipients after two weeks and on the day before the questionnaire closed. The closing date was 16 May 2012, four weeks after the initial invitation was sent.

\section{Analysis of data}

Identifying details from the optional Section 5 of the questionnaire were removed from each response before analysis, to anonymise the data.

Depending on the web browser used and the settings for cookies, the Cvent software used the internet protocol (IP) address to identify where a respondent had partially completed the questionnaire and then returned later. In such cases the answers initially entered were retained, and a single respondent identification number was generated by the software. To check for potential failures in this automatic process, the IP address of each response was also checked manually for duplicates.

Data were exported from the Cvent website to an Excel spread sheet (Microsoft Corp, Redmond, WA, USA) and descriptive analysis was performed. All categorical variables were reported as numbers and percentages. Responses for any open or semi-closed questions that required a simple, factual answer (e.g. sources of information about reporting guidelines) were coded by one author (DG). For open questions that produced complex, freetext responses where quantitative analysis was inappropriate, DG and one other author (RD or MB) undertook independent qualitative analyses to identify themes in the data [34] and code the responses. Agreement on the themes and coding was then reached by discussion where necessary. Hence, these results are reported in a descriptive, and not a numerical, fashion.

\section{Results}

Response rate

From the 197 e-mail addresses on the IAVE list, 16 produced an e-mail failure message after both the first and second attempts. Alternative e-mail addresses were found for eight of these journals and the invitation e-mail resent, but e-mail failure messages were still received for four journals. Hence, it was presumed that the Editors-in-Chief of 185 journals received the e-mail invitation (Appendix 1).

A total of 76 responses were received. Eight responses were identified from the IP address as partial responses where respondents had subsequently answered the questionnaire in full without this being automatically recognised by the Cvent software, so these partial responses were removed from the sample. Therefore 68 usable responses were received from the Editors-in-Chief of the 185 journals contacted, giving a response rate of $36.8 \%$.

\section{Characteristics of respondents}

Optional information on the country of journal publication was provided by 37 of 68 respondents (54.4\%). Seventeen journals were from Europe, eight from North America, five from Asia, six from Africa and one from Australia. The title of their journal was provided by 34 of 68 respondents $(50.0 \%)$.

\section{Previous knowledge of reporting guidelines}

Just under $53 \%(36 / 68)$ of total respondents knew what a reporting guideline was before receiving the questionnaire, while $47.1 \%(32 / 68)$ had no previous knowledge. Thirtytwo of the 36 respondents who knew what a reporting guideline was answered some or all of the supplementary questions that were presented to them in Section 1 of the questionnaire. These editors had mainly learned about reporting guidelines from articles in other journals, by the Internet and through their own journal, with several naming more than one source (Table 1). Of this group, 31.3\% $(10 / 32)$ said they were aware of the EQUATOR Network and its resources on reporting guidelines, compared to $62.5 \%$ (20/32) who were not aware. Seventy-five per cent (24/32) were aware of separate reporting guidelines for different types of studies, and 18.8\% (6/32) were not. Twenty-three respondents specified the guideline(s) with which they were familiar from a supplied list of twelve (Table 2), with CONSORT, ARRIVE and REFLECT being the most cited.

\section{Current journal policies and future plans}

Fifty-seven respondents (83.8\% of total) answered the second compulsory question on whether their journal referred to any reporting guidelines in its instructions to authors. Of these, 35.1\% (20/57) said that their journal 


\section{Table 1 Information sources where Editors-in-Chief of veterinary journals $(n=32)$ learned about reporting guidelines}

\begin{tabular}{lrc}
\hline Information source & $\begin{array}{r}\text { Number of } \\
\text { respondents* }\end{array}$ & $\begin{array}{c}\text { Percentage of } \\
\text { respondents* }\end{array}$ \\
\hline Other journals & 10 & 31.3 \\
Internet & 7 & 21.9 \\
Own journal, including editorial & 6 & 18.8 \\
discussions & 3 & 9.4 \\
Medical literature & 3 & 9.4 \\
Professional colleagues & 2 & 6.3 \\
International Association of Veterinary & & \\
Editors (IAVE) & 2 & 6.3 \\
Postgraduate study & 11 & 34.4 \\
Other sources (one respondent each)† & & \\
\hline
\end{tabular}

*Numbers and percentages add up to more than 32 and $100 \%$ respectively because some respondents named more than one source.

tOther sources were: books, Committee on Publication Ethics (COPE), EQUATOR Network, European Food Safety Authority (EFSA), International Committee of Medical Journal Editors (ICMJE), Journal club, lectures, MEDLINE, National Institutes of Health $(\mathrm{NIH})$, publishers, and reporting guideline authors.

did, 59.6\% (34/57) said that their journal did not, and $5.3 \%(3 / 57)$ said they did not know.

Sixteen of the 20 respondents whose journals referred to reporting guidelines indicated the guidelines used (Table 3). In addition to those reporting guidelines listed in the questionnaire, one respondent specified the

Table 2 Awareness of specific reporting guidelines among Editors-in-Chief of veterinary journals with previous knowledge of reporting guidelines $(n=23)$

\begin{tabular}{|c|c|c|}
\hline Reporting guideline & $\begin{array}{r}\text { Number of } \\
\text { respondents* }\end{array}$ & $\begin{array}{l}\text { Percentage of } \\
\text { respondents* }\end{array}$ \\
\hline $\begin{array}{l}\text { CONSORT (randomised controlled } \\
\text { trials/RCTs) }\end{array}$ & 20 & 87.0 \\
\hline $\begin{array}{l}\text { ARRIVE (research using laboratory } \\
\text { animals) }\end{array}$ & 16 & 69.6 \\
\hline $\begin{array}{l}\text { REFLECT (RCTs for livestock and } \\
\text { food safety) }\end{array}$ & 12 & 52.2 \\
\hline STARD (diagnostic accuracy studies) & 9 & 39.1 \\
\hline $\begin{array}{l}\text { TREND (non-randomised controlled } \\
\text { trials) }\end{array}$ & 9 & 39.1 \\
\hline $\begin{array}{l}\text { PRISMA (systematic reviews and } \\
\text { meta-analyses) }\end{array}$ & 8 & 34.8 \\
\hline COGS (clinical guidelines) & 7 & 30.4 \\
\hline $\begin{array}{l}\text { Gold Standard Publication Checklist } \\
\text { (animal research) }\end{array}$ & 6 & 26.1 \\
\hline STROBE (observational studies) & 6 & 26.1 \\
\hline COREQ (qualitative research) & 4 & 17.4 \\
\hline $\begin{array}{l}\text { MOOSE (meta-analyses of observational } \\
\text { studies in epidemiology) }\end{array}$ & 3 & 13.0 \\
\hline STREGA (genetic association studies) & 2 & 8.7 \\
\hline
\end{tabular}

*Numbers and percentages add up to more than 23 and 100\% respectively because some respondents were aware of more than one reporting guideline.
Table 3 Reporting guidelines mentioned in the instructions to authors of veterinary journals $(n=16)$

\begin{tabular}{|c|c|c|}
\hline Reporting guideline & $\begin{array}{l}\text { Number of } \\
\text { journals* }\end{array}$ & $\begin{array}{l}\text { Percentage of } \\
\text { respondents* }\end{array}$ \\
\hline ARRIVE (research using laboratory animals) & 4 & 25.0 \\
\hline $\begin{array}{l}\text { CONSORT (randomised controlled } \\
\text { trials/RCTs) }\end{array}$ & 4 & 25.0 \\
\hline $\begin{array}{l}\text { REFLECT (RCTs for livestock and food } \\
\text { safety) }\end{array}$ & 4 & 25.0 \\
\hline $\begin{array}{l}\text { PRISMA (systematic reviews and } \\
\text { meta-analyses) }\end{array}$ & 3 & 18.8 \\
\hline STARD (diagnostic accuracy studies) & 3 & 18.8 \\
\hline STROBE (observational studies) & 3 & 18.8 \\
\hline $\begin{array}{l}\text { ICMJE (Uniform Requirements for } \\
\text { Manuscripts Submitted to Biomedical } \\
\text { Journals) }\end{array}$ & 2 & 12.5 \\
\hline $\begin{array}{l}\text { ORION (outbreak reports and intervention } \\
\text { studies of nosocomial infection) }\end{array}$ & 1 & 6.3 \\
\hline
\end{tabular}

*Numbers and percentages add up to more than 16 and $100 \%$ respectively because some journals referred to more than one reporting guideline.

ORION statement for studies of outbreaks and nosocomial infections [35], and two respondents cited the International Committee of Medical Journal Editors (ICMJE) Uniform Requirements for manuscripts submitted to biomedical journals [36]. Five respondents cited only the author guidelines for their own journal rather than consensus reporting guidelines for different study types. Nine $(45 \%)$ of the 20 respondents whose journal referred to reporting guidelines said they had plans to implement additional reporting guidelines in the future.

Fifteen respondents whose journals referred to reporting guidelines in their instructions to authors indicated what they did with submitted studies that did not follow the relevant reporting guideline, but otherwise satisfied their editorial criteria. Three editors said they would be rejected, 11 said they would be returned to the authors to modify in line with the reporting guideline, and one editor said they did nothing, but relied on the reviewers' comments.

For respondents whose journal did not refer to reporting guidelines, the reasons given included the opinion that existing instructions to authors and review processes were sufficient, and that reporting guidelines were not appropriate for the types of article submitted to their journal. Lack of personal knowledge or previous consideration of reporting guidelines by the editors themselves, the setting of policy by the publisher, and the belief that reporting was a responsibility for authors were other themes in the data. It was also suggested that existing reporting guidelines were difficult to implement and would place an undue burden on reviewers.

Respondents whose journal did not refer to reporting guidelines in their instructions to authors were asked if their journal had plans to implement reporting 
guidelines in the future. Of these respondents, $29.4 \%$ (10/34) responded "Yes", 17.6\% (6/34) responded "No", 35.3\% (12/34) responded "Don't know", and $17.6 \%(6 / 34)$ did not respond.

Views on the need to implement reporting guidelines Forty-four respondents (65.7\% of total) answered the question on whether they believed that reporting guidelines should be adopted by all refereed veterinary journals. Of these, $68.2 \%$ (30/44) believed they should, 11.4\% (5/44) believed they should not, and 20.5\% (9/44) said they did not know.

In response to the open questions, the main reasons given by those believing they should be adopted by all refereed veterinary journals were that guidelines would improve the quality of reporting of research, would ensure consistency of standards across studies and across journals, and provide a guide to reviewers and authors. One respondent commented: "If all journals started to emphasise reporting, ultimately authors would start to consider these aspects in their study design at the planning stage".

The themes arising from the responses of those who thought reporting guidelines should not be adopted by all refereed veterinary journals included the belief that the current system was satisfactory, that there should be "a freedom for editors and authors to have other ways of ensuring high quality work", that reporting guidelines did not suit all subject areas or study types, and that authors might be hesitant to submit to journals that applied the guidelines strictly.

\section{Factors preventing the adoption of reporting guidelines}

The most common theme arising in responses to the open question about factors preventing the adoption of reporting guidelines was a lack of knowledge among authors, reviewers and editors. The influence of "tradition", fear or resistance to change within the veterinary community was also widely mentioned, as well as concern about cultural differences between journals and between countries, the increased workload that could be caused, and economic factors. Another theme was the belief that authors would prefer journals without reporting guidelines, leading to a fear of losing submissions if a journal were to adopt them. One editor referred to "the current need to accept/publish minor quality papers even in higher ranking veterinary journals", and another referred to the "publish or perish syndrome" as potential factors preventing the adoption of reporting guidelines.

\section{Factors or actions that would promote more widespread adoption of reporting guidelines}

A common theme on factors to promote more widespread adoption of reporting guidelines was communication and increased awareness amongst the veterinary community, with roles proposed for the IAVE, EQUATOR Network and Centre for Evidence-based Veterinary Medicine. Suggested ways to increase awareness included promotion on the Internet, information and links on journal websites, editorials, conferences and targeting authors from developing countries. The importance of education and continuing professional development for all involved in the authoring and publishing process was highlighted, including a specific role for universities in educating veterinary students and young researchers about reporting guidelines. It was suggested that there should be a consensus policy among veterinary journals on guideline implementation, with the IAVE involved. There were conflicting opinions on who should "enforce" guidelines, whether editors or authors, through "pressure" on journals.

Several respondents indicated that this survey had in itself made them aware of reporting guidelines. One respondent commented: "It made me think about several aspects of our journals and how can we improve our researchers' capability to report accurately their findings".

\section{Information needs}

Of the 42 editors who answered the question on whether more information about reporting guidelines would be useful, 37 (88.1\%) said "Yes" and five (11.9\%) said "No". In the open responses, the most suggested ways to disseminate information on reporting guidelines to veterinary editors were by e-mail, meetings, and websites. Editorials, articles and educational activities were also mentioned. Again several respondents indicated that the IAVE should play a part.

\section{Discussion}

Major findings of this study were that nearly half of the responding Editors-in-Chief had not previously heard about reporting guidelines, and that only around a third of their journals referred to reporting guidelines in their instructions to authors. This lack of awareness is likely to be a barrier to their widespread implementation by veterinary journals.

Among the Editors-in-Chief who were aware of reporting guidelines, CONSORT, REFLECT, and ARRIVE were the most widely-known, and these were also the most frequently mentioned guidelines in instructions to authors according to the survey. This may reflect the types of studies published in many veterinary journals (randomised controlled trials and experimental animal studies) or the ways in which information about these guidelines has been disseminated. CONSORT is one of the most widely cited reporting guidelines in the medical literature and has undergone evaluation and revision over time [37]. There have been several commentaries in veterinary journals focusing on CONSORT [24,25,30,32], 
REFLECT [30,32,38] and ARRIVE [39]. Such promotion is likely to have contributed to awareness and implementation of these guidelines by veterinary editors.

Although their journal's instructions to authors were considered as a type of reporting guideline by five editors in this survey, author guidelines do not usually provide the detailed information necessary for complete and accurate reporting of individual study types, and do not reflect a consensus among experts. Two editors cited the ICMJE Uniform Requirements [36] as their journal's reporting guidelines, but this document mainly addresses editing and ethical issues rather than reporting. If these seven respondents are excluded from our analysis, the proportion of veterinary journals that referred to reporting guidelines decreases from $35.1 \%$ to $22.8 \%$.

Implementation of guidelines by journals can occur in several ways-inclusion in instructions to authors, inclusion in instructions to reviewers, and the use of reporting guideline checklists for authors and referees [28,40]. There is also the possibility of editors rejecting papers that do not meet the relevant guideline $[2,28]$, although Vandenbroucke [40] suggested it may not be practical for editors to do the checking. It is therefore noteworthy that in this survey almost all the Editors-in-Chief whose journal referred to reporting guidelines in author instructions said that non-complying articles would be rejected or returned to authors for amendment.

A recent systematic review found that medical journal endorsement of CONSORT was insufficient to ensure the completeness of reporting [37], and two studies found that the quality of articles on studies of diagnostic accuracy did not notably improve when STARD was included in author guidelines, largely because of lack of adherence to those guidelines [41,42]. In another study, authors found it difficult to adhere to high methodological standards after the research had already been done [43]. This highlights the importance of undergraduate and postgraduate education on reporting guidelines, as suggested in our survey and elsewhere $[26,28]$. Reporting guidelines also appear to be underutilised by peer reviewers for medical journals [44], and reviewers and editors sometimes overlook lack of adherence to reporting guidelines to publish for other reasons [41]. Thus, it will be important to monitor the methods and impact of implementation if more veterinary journals adopt reporting guidelines in the future.

It is notable that some respondents believed that reporting guidelines were not necessary, or that their own guidelines and review process were enough to ensure the quality of published papers. Yet analyses of published veterinary research suggest there is room for improvement [19-23] and the quality of reported research has been improved in medical journals where reporting guideline checklists were utilised [5-8]. There were also editors in this survey who expressed the fear that reporting guidelines would limit the freedom of journals and authors, and that enforcement would mean a loss of authors and manuscripts to other journals. Such concerns and resistance to reporting guidelines have been echoed by editors of medical journals [40]. Gradual implementation of reporting guidelines could give authors the chance to improve their study design in anticipation of reporting requirements. Another solution, proposed by respondents in this survey, would be to achieve a consensus on the implementation of reporting guidelines among veterinary journals, as has also been suggested for medical journals [40].

Our survey results indicate that two-thirds of Editorsin-Chief believed that reporting guidelines should be adopted by all peer-reviewed journals, and many expressed an interest in receiving more information about reporting guidelines. Thus, more effective dissemination of information to editors and authors and a better understanding of the relevance of reporting guidelines to veterinary research have strong potential to increase their adoption by veterinary journals in the future. A relatively high proportion of respondents learned about reporting guidelines through other journals, so editorials and the republication of reporting guidelines appear to be effective ways of disseminating information about their use and applicability in different disciplines. Many respondents mentioned the Internet as a source of information-there is scope to increase awareness of the resources for editors on the EQUATOR Network [9] and IAVE [45] websites. Similar findings about the need for dissemination of information to editors, including education and provision of electronic resources, were found in a recent survey of medical journal editors on implementation of the CONSORT guidelines [46]. A more proactive approach to dissemination seems warranted, including direct contact with veterinary editors. This survey has in itself been part of the process, according to some of the participants.

\section{Limitations of the study}

The response rate of $36.8 \%$ for this survey was comparable to the response rates of $27.6 \%$ and $39 \%$ obtained by Shamseer et al. [46] and Hopewell et al. [47] respectively in their surveys of medical journal editors about CONSORT. One possible reason for non-responses in this survey could have been language, as many journals in the IAVE list (Appendix 1) are based in non-English speaking countries and are not published in English. Reporting guidelines are also heavily focused on epidemiologic study design and clinical medicine, which are not well-developed disciplines in veterinary medicine in all countries. Another potential reason for non-responses is that some veterinary journals are not peer-reviewed or do not publish original 
research, so reporting guidelines would not be so relevant for their editors.

A possible limitation to this study is that survey recipients with an awareness of, or interest in, reporting guidelines might be more likely to respond. The results might therefore have been questionable if the survey had found a high degree of awareness of reporting guidelines among the respondents. However, it is clear from the actual data that there were considerable numbers of Editors-in-Chief who were previously unaware of reporting guidelines, with potentially more among the nonrespondents.

Another potential issue is that it was possible for respondents to go back and change their answer to Question 1, "Before receiving this questionnaire, did you know what a reporting guideline/standard was", after they saw the explanation of reporting guidelines later in the questionnaire. Some respondents may not have answered truthfully if they thought this was knowledge they should possess. However, the answers to Question 1 could also have been refined in cases where respondents were familiar with the concept of reporting guidelines, but did not initially recognise the term in Question 1.

As the questionnaire could be answered anonymously, it was not possible to obtain information about all respondents and to determine whether they were representative of the population of journals in the IAVE database. Anonymity was felt to be important to ensure an adequate response rate, because the survey was partly about the editors' personal knowledge and views on a potentially sensitive topic. Indeed, since only around half of the responding editors chose to identify themselves, this suggests that the response rate would have been lower had disclosure been required. Importantly, those Editors-in-Chief who did provide identifying details represented a wide range of geographical locations.

This survey is subject to reporting bias, as respondents were asked to report what they do, which may not be what they actually do in practice. Only an examination of the instructions to authors for all the journals in the sampling frame would provide a completely accurate assessment of current practice.

\section{Conclusions}

The results of this survey provide valuable information on the awareness, knowledge, policies, and views of veterinary journal Editors-in-Chief about reporting guidelines, and perceived barriers to their adoption by veterinary journals. Editors have an important leadership role in the implementation of reporting guidelines and improving the quality of research reporting, yet many appear to have little or no knowledge of reporting guidelines. More effective communication and education about reporting guidelines for editors, reviewers and authors has strong potential to increase their adoption by veterinary journals in the future.

\section{Appendix}

Appendix 1 - Journals on the International Association of Veterinary Editors (IAVE) e-mail list whose Editors-in-Chief were presumed to have received the survey invitation $(n=185)$

Acta Scientiae Veterinariae

Acta Veterinaria (Beograd)

Acta Veterinaria Brno

Acta Veterinaria Hungarica

Acta Veterinaria Scandinavica

Advances in Small Animal Medicine and Surgery

Alexandria Journal of Veterinary Sciences

Anatomia, Histologia, Embryologia

Animal

Animal Behaviour

Animal Biotechnology

Animal Genetics

Animal Health Research Reviews

Animal Reproduction Science

Animal Welfare

Annales de Médecine Vétérinaire

Anthrozöos

Archives of Veterinary Science

Archivos de Medicina Veterinaria

Arquivo Brasileiro de Medicina Veterinária e Zootecnia

Australian Cattle Veterinarians

Australian Veterinary Journal

Avian Diseases

Avian Pathology

Berliner und Münchener Tierärzliche Wochenschrift

BMC Veterinary Research

Brazilian Journal of Veterinary Research and Animal

Science

Bulgarian Journal of Veterinary Medicine

Bulletin of Animal Health and Production in Africa

Canadian Journal of Veterinary Research

Canadian Veterinary Journal

Ciência e Agrotecnologia

Clinician's Brief

Comparative Clinical Pathology

Comparative Exercise Physiology

Comparative Immunology, Microbiology, and Infectious

Diseases

Comparative Medicine

Danish Veterinary Journal/Dansk Veterinærtidsskrift

Diseases of Aquatic Organisms

Domestic Animal Endocrinology

Egyptian Journal of Comparative Pathology and Clinical

Pathology

Egyptian Journal of Sheep and Goat Sciences 
Equine Veterinary Education

Equine Veterinary Journal

Estonian Veterinary Review

European Journal of Companion Animal Practice

Finnish Veterinary Journal/Suomen Eläinlääkärilehti

Flemish Veterinary Journal/Vlaams Diergeneeskundig

Tijdschrift

Folia Veterinaria

Hungarian Veterinary Journal/Magyar Âllatorvosok Lapja

ILAR Journal

Indian Veterinary Journal

International Journal of Applied Research in Veterinary

Medicine

International Journal of Veterinary Research

Internet Journal of Veterinary Medicine

Ippologia

Iranian Journal of Veterinary Research

Iraqi Journal of Veterinary Sciences

Irish Veterinary Journal

Israel Journal of Veterinary Medicine

Japanese Journal of Veterinary Research

Journal of Advanced Research

Journal of the American Animal Hospital Association

Journal of the American Veterinary Medical Association

/ American Journal of Veterinary Research

Journal of Animal Breeding and Genetics

Journal of Animal Physiology and Animal Nutrition

Journal of Applied Animal Welfare Science

Journal of Aquatic Animal Health

Journal of Avian Medicine and Surgery

Journal of Camel Practice and Research

Journal of Comparative Pathology

Journal of the Egyptian Veterinary Medical Society of

Parasitology

Journal of Equine Veterinary Science

Journal of Exotic Pet Medicine

Journal of Feline Medicine and Surgery

Journal of Fish Diseases

Journal of the Hellenic Veterinary Medical Society/

Deltion tes Ellenikes Kteniatrikes Etaireias

Journal of Herpetological Medicine and Surgery

Journal of Medical Primatology

Journal of Small Animal Practice

Journal of the South African Veterinary Association

Journal of Swine Health and Production

Journal of Veterinary and Animal Sciences

Journal of Veterinary Behavior: Clinical Applications

and Research

Journal of Veterinary Cardiology

Journal of Veterinary Dentistry

Journal of Veterinary Diagnostic Investigation

Journal of Veterinary Emergency and Critical Care

Journal of Veterinary Internal Medicine

Journal of Veterinary Medical Education
Journal of Veterinary Medical Science

Journal of Veterinary Pharmacology and Therapeutics

Journal of Veterinary Research

Journal of Veterinary Science

Journal of Veterinary Science and Technology

Journal of Wildlife Diseases

Journal of Wildlife Rehabilitation

Journal of Zoo and Wildlife Medicine

Kafkas Üniversitesi Veteriner Fakültesi Dergisi

Kafr-El-Sheikh Veterinary Medical Journal

Kenya Veterinarian

Kleintiermedizin

Kleintierpraxis

Laboratory Animals

Magazyn Weterynaryjny

Medical and Veterinary Entomology

Medycyna Weterynaryjna

New Zealand Veterinary Journal

Nigerian Veterinary Journal

Norwegian Veterinary Journal/Norsk Veterinærtidsskrift

Onderstepoort Journal of Veterinary Research

Online Journal of Veterinary Research

Pakistan Veterinary Journal

Pesquisa Veterinária Brasileira

Pferdeheilkunde

Philippine Journal of Veterinary and Animal Sciences

Pig Journal

Point Vétérinaire

Polish Journal of Veterinary Sciences

Praktische Tierarzt

Pratique Medicale et Chirurgicale de l'Animal de Compagnie

Preventive Veterinary Medicine

Production Animales (INRA)

Reproduction in Domestic Animals

Research in Veterinary Science

Revista de Ciências Agroveterinárias (Journal of

Agronomy and Veterinary Sciences)

Revista do Centro de Ciências Rurais

Revista Mexicana de Ciencias Pecuarias

Revista Veterinária Notícias

Revue de Médecine Vétérinaire

Revue Scientifique et Technique (International Office of Epizootics)

Sahel Journal of Veterinary Sciences

Scandinavian Journal of Laboratory Animal Science

Schweizer Archiv für Tierheilkunde/SAT

Sheep and Goat Research Journal

Slovenian Veterinary Research

Small Ruminant Research

Suez Canal Veterinary Medical Journal

Swedish Veterinary Journal/Svensk Veterinärtidning

Tanzania Veterinary Journal

Thai Journal of Veterinary Medicine 
Theriogenology

Tieraerztliche Praxis (Grosstiere)

Tieraerztliche Praxis (Kleintiere)

Tijdschrift voor Diergeneeskunde

Today's Veterinarian

Topics in Companion Animal Medicine

Transboundary and Emerging Diseases

Tropical Animal Health and Production

Tropical Veterinarian

Turkish Journal of Veterinary and Animal Sciences

Vet On-Line

Veterinaria México

Veterinarija ir Zootechnika

Veterinarski Arhiv

Veterinárství

Veterinary Anaesthesia and Analgesia

Veterinary and Comparative Oncology

Veterinary Bulletin

Veterinary Clinical Pathology

Veterinary and Comparative Orthopaedics and

Traumatology

Veterinary Dermatology

Veterinary Economics

Veterinary Immunology and Immunopathology

Veterinary Journal

Veterinary Medicine: Research and Reports

Veterinary Medicine

Veterinary Microbiology

Veterinary Ophthalmology

Veterinary Parasitology

Veterinary Pathology

Veterinary Quarterly

Veterinary Radiology and Ultrasound

Veterinary Record

Veterinary Research (Pakistan)

Veterinary Research (BioMed Central)

Veterinary Research Communications

Veterinary Sciences Tomorrow

Veterinary Surgery

Veterinary Therapeutics

Veterinary World

West Indian Veterinary Journal

Wiener Tierärztliche Monatsschrift

Zoo Biology

Zoonoses and Public Health

\section{Additional file}

Additional file 1: Questionnaire on reporting guidelines for veterinary Editors-in-Chief.

\section{Competing interests}

MC founded and co-ordinates the International Association of Veterinary Editors, which receives financial support from Wiley and Elsevier. MC is also the former Editor-in-Chief of Veterinary Clinical Pathology.

\section{Authors' contributions}

DG participated in the design of the study, drafted the questionnaire, analysed the data and drafted the manuscript. RD participated in the design of the study, helped to draft the questionnaire, coded data and helped to draft the manuscript. MB participated in the design of the study, helped to draft the questionnaire, coded data and helped to draft the manuscript. MC participated in the design of the study, tested the questionnaire, distributed the invitation to Editors-in-Chief and helped to draft the manuscript. All authors read and approved the final manuscript.

\section{Acknowledgements}

The authors express their sincere thanks to the Editors-in-Chief who took part in this survey. The Centre for Evidence-based Veterinary Medicine is supported by an unrestricted grant from Novartis Animal Health and The University of Nottingham.

\section{Author details}

${ }^{1}$ Centre for Evidence-based Veterinary Medicine, School of Veterinary Medicine and Science, The University of Nottingham, Sutton Bonington Campus, Loughborough LE12 5RD, UK. ² School of Veterinary Medicine, 4206 VM3A, University of California-Davis, One Shields Ave, Davis, CA 95616, USA

Received: 5 August 2013 Accepted: 26 November 2013

Published: 10 January 2014

References

1. EQUATOR Network: Introduction to reporting guidelines. http://www.equatornetwork.org/toolkits/teachers/teachers-introduction-to-reporting-guidelines/.

2. More SJ: Improving the quality of reporting in veterinary journals: how far do we need to go with reporting guidelines? Vet J 2010, 184:249-250.

3. Simera I, Moher D, Hirst A, Hoey J, Schulz KF, Altman DG: Transparent and accurate reporting increases reliability, utility, and impact of your research: reporting guidelines and the EQUATOR Network. BMC Med 2010, 8:24

4. Larson EL, Cortazal M: Publication guidelines need widespread adoption. J Clin Epidemiol 2012, 65:239-246.

5. Moher D, Jones A, Lepage L, CONSORT Group (Consolidated Standards for Reporting of Trials): Use of the CONSORT statement and quality of reports of randomized trials: a comparative before-and-after evaluation. JAMA 2001, 285:1992-1995.

6. Lumbreras-Lacarra B, Ramos-Rincón JM, Hernández-Aguado I: Methodology in diagnostic laboratory test research in clinical chemistry and clinical chemistry and laboratory medicine. Clin Chem 2004, 50:530-536.

7. Plint AC, Moher D, Morrison A, Schulz K, Altman DG, Hill C, Gaboury I: Does the CONSORT checklist improve the quality of reports of randomised controlled trials? A systematic review. Med J Aust 2006, 185:263-267.

8. Kane RL, Wang J, Garrard J: Reporting in randomized clinical trials improved after adoption of the CONSORT statement. J Clin Epidemiol 2007, 60:241-249.

9. EQUATOR Network: Library for health research reporting. http://www.equatornetwork.org/library/.

10. Popham K, Calo WA, Carpentier MY, Chen NE, Kamrudin SA, Le YC, Skala KA, Thornton LR, Mullen PD: Reporting guidelines: optimal use in preventive medicine and public health. Am J Prev Med 2012, 43:e31-e42.

11. Schulz KF, Altman DG, Moher D, CONSORT Group: CONSORT 2010 statement: updated guidelines for reporting parallel group randomised trials. BMJ 2010, 340:c332.

12. Des Jarlais DC, Lyles C, Crepaz N, TREND Group: Improving the reporting quality of nonrandomized evaluations of behavioral and public health interventions: the TREND statement. Am J Public Health 2004, 94:361-366.

13. von Elm E, Altman DG, Egger M, Pocock SJ, Gøtzsche PC, Vandenbroucke JP, STROBE initiative: Strengthening the reporting of observational studies in epidemiology (STROBE) statement: guidelines for reporting observational studies. BMJ 2007, 335:806-808.

14. Moher D, Liberati A, Tetzlaff J, Altman DG, PRISMA Group: Preferred reporting items for systematic reviews and meta-analyses: the PRISMA statement. BMJ 2009, 339:b2535.

15. Bossuyt PM, Reitsma JB, Bruns DE, Gatsonis CA, Glasziou PP, Irwig LM, Lijmer JG, Moher D, Rennie D, de Vet HC: Standards for reporting of diagnostic accuracy: towards complete and accurate reporting of studies of diagnostic accuracy: the STARD initiative. Clin Chem 2003, 49:1-6. 
16. Sargeant JM, O'Connor AM, Gardner IA, Dickson JS, Torrence ME, Consensus meeting participants: The REFLECT statement: reporting guidelines for randomized controlled trials in livestock and food safety: explanation and elaboration. Zoonoses Public Health 2010, 57:105-136.

17. Kilkenny C, Browne WJ, Cuthill IC, Emerson M, Altman DG: Improving bioscience research reporting: the ARRIVE guidelines for reporting animal research. PLOS Biol 2010, 8:e1000412.

18. International Association of Veterinary Editors: Consensus author quidelines on animal ethics and welfare for veterinary journals. http://www.veteditors. org/IAVE-AuthorGuidelines.pdf.

19. Nielsen SS, Toft N: Ante mortem diagnosis of paratuberculosis: a review of accuracies of ELISA, interferon-gamma assay and faecal culture techniques. Vet Microbio/ 2008, 129:217-235.

20. Sargeant JM, Elgie R, Valcour J, Saint-Onge J, Thompson A, Marcynuk P, Snedeker K: Methodological quality and completeness of reporting in clinical trials conducted in livestock species. Prev Vet Med 2009, 91:107-115.

21. O'Connor AM, Wellman NG, Rice M, Funk L: Characteristics of clinical trials assessing antimicrobial treatment of bovine respiratory disease, 1970-2005. J Am Vet Med Assoc 2010, 237:701-705.

22. Sargeant JM, Thompson A, Valcour J, Elgie R, Saint-Onge J, Marcynuk P, Snedeker K: Quality of reporting of clinical trials of dogs and cats and associations with treatment effects. J Vet Intern Med 2010, 24:44-50.

23. Simoneit C, Heuwieser W, Arlt S: Evidence-based medicine in bovine, equine and canine reproduction: quality of current literature. Theriogenology 2011, 76:1042-1050.

24. Lakhani $\mathrm{KH}$ : Inductive inference and experimental designs: the CONSORT and QUOROM statements. Vet J 2001, 161:102-103.

25. Revington ML: Improving the reporting of clinical trials: the CONSORT statement. Aust Vet J 2003, 81:532-534.

26. Christopher MM: Improving the quality of reporting of studies of diagnostic accuracy: let's STARD now. Vet Clin Pathol 2007, 36:6.

27. Boden LA, Parkin TD: Current guidelines on good reporting of analytical observational studies in epidemiology. Equine Vet J 2008, 40:84-86.

28. Erb HN: Changing expectations: Do journals drive methodological changes? Should they? Prev Vet Med 2010, 97:165-174

29. Gardner IA: Quality standards are needed for reporting of test accuracy studies for animal diseases. Prev Vet Med 2010, 97:136-143.

30. Hinchcliff KW, DiBartola SP: Quality matters: publishing in the era of CONSORT, REFLECT, and EBM. J Vet Intern Med 2010, 24:8-9.

31. O'Connor A: Reporting guidelines for primary research: saying what you did. Prev Vet Med 2010, 97:144-149.

32. Rishniw M, Pion PD, Herndon WE, Barr SC, de Lorimier LP, Rosenthal R, Katherman A, Vasilopulos R, Gunn-Christie R, Thamm D, Kube S, Speer B, Freshman J, Scherk M, Schmidt R, Datz C, Wolf A, Griffith D, Palmquist R, Harr K, Niessen S, Simpson K, Morgan R, Peterson M, Daugherty J: Improving reporting of clinical trials in veterinary medicine. J Vet Intern Med 2010, 24:799-800.

33. Blomme EA: The ARRIVE guidelines: a resource for authors and reviewers to ensure that submissions to The Veterinary Journal meet minimal expectations of completeness, accuracy and transparency. Vet J 2011, 189:237-238.

34. Attride-Stirling J: Thematic networks: an analytical tool for qualitative research. J Qual Res 2001, 1:385-405.

35. Stone SP, Cooper BS, Kibbler CC, Cookson BD, Roberts JA, Medley GF, Duckworth G, Lai R, Ebrahim S, Brown EM, Wiffen PJ, Davey PG: The ORION statement: guidelines for transparent reporting of outbreak reports and intervention studies of nosocomial infection. Lancet Infect Dis 2007, 7:282-288.

36. International Committee of Medical Journal Editors: Uniform requirements for manuscripts submitted to biomedical journals. http://www.icmje.org.

37. Turner L, Shamseer L, Altman DG, Schulz KF, Moher D: Does use of the CONSORT statement impact the completeness of reporting of randomised controlled trials published in medical journals? A Cochrane review. Syst Rev 2012, 1:60

38. REFLECT Reporting Guidelines for Randomized Controlled Trials in Livestock and Food Safety: News. http://www.reflect-statement.org/news/.

39. National Centre for the Replacement, Refinement and Reduction of Animals in Research: ARRIVE guidelines. http://www.nc3rs.org.uk/page.asp?id=1357.
40. Vandenbroucke JP: STREGA, STROBE, STARD, SQUIRE, MOOSE, PRISMA, GNOSIS, TREND, ORION, COREQ, QUOROM, REMARK... and CONSORT: for whom does the guideline toll? J Clin Epidemiol 2009, 62:594-596.

41. Coppus SF, van der Veen F, Bossuyt PM, Mol BW: Quality of reporting of test accuracy studies in reproductive medicine: impact of the standards for reporting of diagnostic accuracy (STARD) initiative. Fertil Steril 2006, 86:1321-1329.

42. Smidt N, Rutjes AW, van der Windt DA, Ostelo RW, Bossuyt PM, Reitsma JB, Bouter LM, de Vet HC: The quality of diagnostic accuracy studies since the STARD statement: has it improved? Neurology 2006, 67:792-797.

43. Cobo E, Cortés J, Ribera JM, Cardellach F, Selva-O'Callaghan A, Kostov B, García L, Cirugeda L, Altman DG, González JA, Sànchez JA, Miras F, Urrutia A, Fonollosa $V$, Rey-Joly C, Vilardell M: Effect of using reporting guidelines during peer review on quality of final manuscripts submitted to a biomedical journal: masked randomised trial. BMJ 2011, 343:d6783.

44. Hirst A, Altman DG: Are peer reviewers encouraged to use reporting guidelines? A survey of 116 health research journals. PLoS One 2012 7:e35621.

45. International Association of Veterinary Editors: http://www.veteditors.org.

46. Shamseer L, Weeks L, Turner L, Straus S, Grimshaw J, Moher D: Identifying barriers to uptake and implementation of CONSORT. In Seventh International Congress on Peer Review and Biomedical Publication, Plenary Session Abstracts. Chicago; 2013:35. http://www.peerreviewcongress.org/ 2013/Plenary-Session-Abstracts-9-10.pdf

47. Hopewell S, Altman DG, Moher D, Schulz KF: Endorsement of the CONSORT Statement by high impact factor medical journals: a survey of journal editors and journal 'Instructions to Authors'. Trials 2008, 9:20.

\section{doi:10.1186/1746-6148-10-10}

Cite this article as: Grindlay et al:: A survey of the awareness, knowledge, policies and views of veterinary journal Editors-in-Chief on reporting guidelines for publication of research. BMC Veterinary Research 2014 10:10.

\section{Submit your next manuscript to BioMed Central and take full advantage of:}

- Convenient online submission

- Thorough peer review

- No space constraints or color figure charges

- Immediate publication on acceptance

- Inclusion in PubMed, CAS, Scopus and Google Scholar

- Research which is freely available for redistribution 